\title{
Hydrodynamic Analysis of Jack-up Platform in the Spud-can Driving and Pulling Conditions
}

\author{
Zhao-De ZHANG ${ }^{1, a}$, Yu-Hong WANG \\ ${ }^{1}$ School of Naval Architecture and Ocean Engineering, Zhejiang Ocean University, Zhoushan, \\ Zhejiang 316022, P.R. China \\ azhangzhaode@163.com, b24634963@qq.com
}

\author{
Keywords: Jack-up Platform, Hydrodynamic Response, FEM, Wave.
}

\begin{abstract}
The dynamic responses of jack-up platform, in floating state, are calculated numerically. The finite element models of a jack-up are made. And the dynamic responses of the jack-up are simulated when the spud-can is driving downwards at different depths while the jack-up platform is floating on the sea[1]. The responses sensitivity of different waves are also analyzed. The results show that the responses, especially the heave, surge and sway are much larger than other degrees of freedom, during the floating state. The roll and pitch become smaller, when the depth of the spud-can increases. While the heave of the platform becomes larger when the depth of the spud-can increases in the pile driving process. Different degree of freedoms are sensitive differently to different wave directions.
\end{abstract}

\section{Introduction}

Jack-up rigs are used in drilling or remedial works for marine oil, in the depth from several meters to one or two hundred meters[2]. Because it is not self-propelled, the platform must be towed by tugboats before it began to work on the sea. When the platform is pulled to the working site, the next procedure is spud driving. The pile and the spud-can will be put downwards until it touches down the seabed. And when the jack-up ends its job at this position, the spud-can will be pulled up from the sea floor[3,4,5]. In the periods of spud driving and spud pulling, the platform is in the free floating condition. At this time, when waves and currents are coming, the platform will move in the six degrees of freedom. If the movement gets larger, it may threaten the safety of the structure[6,7].

In this paper, the finite element models are made. And the dynamic responses of the jack-up are simulated in the condition of spud driving and spud pulling in the sea[1]. The response sensitivity of different wave directions is also calculated. The results show that the heave, surge and sway response are larger than other degrees of freedom, particularly, during the floating state. Different degrees of freedom are sensitive differently to different wave directions.

\section{The Calculation Model of Jack-up}

The main dimensions of the jack-up platform are $\mathrm{L}=39 \mathrm{~m}, \mathrm{~B}=36 \mathrm{~m}, \mathrm{D}=4.6 \mathrm{~m}$. The elevation view layout of the platform is shown as Fig.1. The vertical view layout of the platform is shown as Fig.2. The three legs of the platform are raised up during the towing state. And when the jack-up gets to the working position, the piles are driven downwards under the sea level, until the spud-can touches down the seabed[8,9]. After the piles touch the bottom, the platform will be raised up steadily while the piles are driven downwards constantly. Before the spud-can touches the sea floor, the platform is floating on the surface of the sea. The waves and currents will cause the platform to move in six degrees of freedom[10]. The dynamic responses of the vessel can be calculated by using SESAM software.

According to the environment conditions of Bohai Bay in the northeast of China, the load cases of the jack-up platform are designed as shown in Table1. The direction of incident waves is shown as Fig.3. 


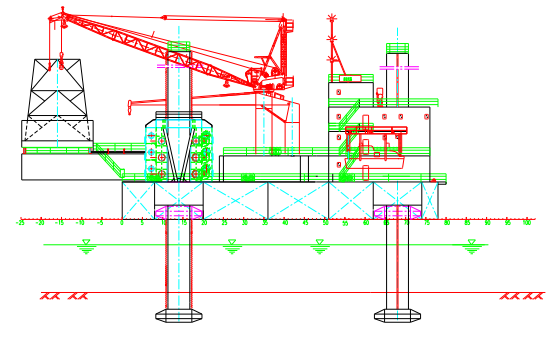

Fig. 1 The Layout Of the Jack-up (Elevation View)

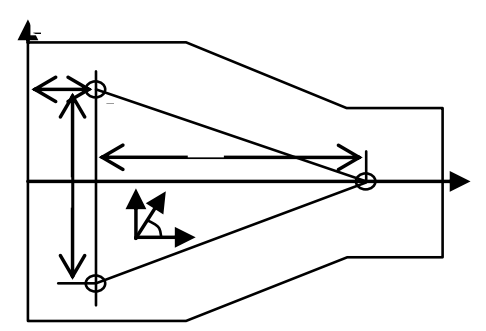

Fig. 2 The Layout of Jack-up (Vertical View)

Tab.1 Calculation Load Cases

\begin{tabular}{|c|c|c|}
\hline $\begin{array}{c}\text { Load } \\
\text { case }\end{array}$ & $\begin{array}{c}\text { Water } \\
\text { depth(m) }\end{array}$ & $\begin{array}{c}\text { Pile } \\
\text { length in } \\
\text { water(m) }\end{array}$ \\
\hline LC1 & 40 & 3 \\
\hline LC2 & 40 & 10 \\
\hline LC3 & 40 & 20 \\
\hline LC4 & 40 & 38 \\
\hline
\end{tabular}

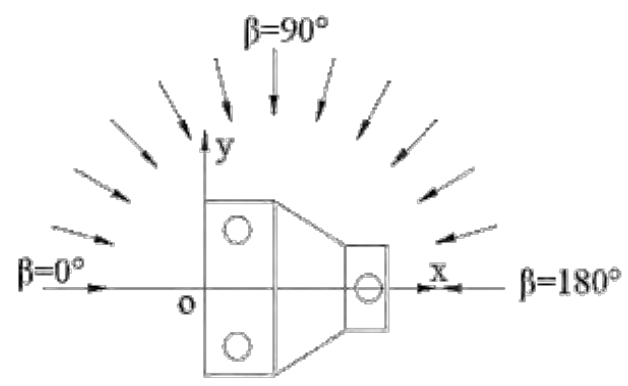

Fig. 3 The Direction of Incident Wave

In load case 1, the piles are in the highest position, the calculating model in SESAM/GeniE is shown in Fig. 4. The model in SESAM/HydroD is shown in Fig.5.

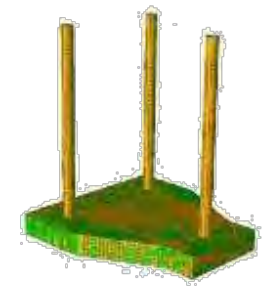

Fig. 4 Model in GeniE

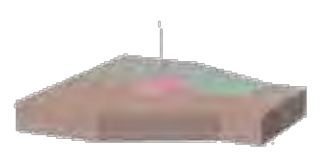

Fig. 5Model in HydroD

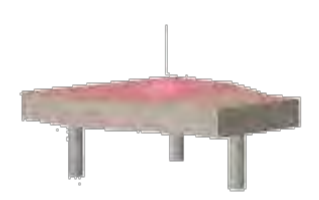

Fig. 6 Model in GeniE

In load case 2, the depth of the spun-can is $10 \mathrm{~m}$, the calculating model in SESAM/GeniE is shown as Fig. 6. The model in SESAM/HydroD is shown in Fig.7.

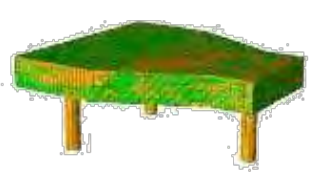

Fig. 7 Model in HydroD

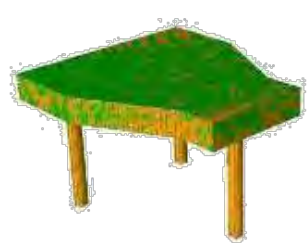

Fig. 8 Model in GeniE

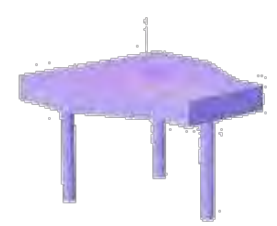

Fig. 9 Model in HydroD 
In load case 3 , the depth of the spun-can is $20 \mathrm{~m}$, the calculating model in SESAM/GeniE is shown in Fig. 8. The model in SESAM/HydroD is shown as Fig. 9.

In load case 4 , the depth of the spun-can is $38 \mathrm{~m}$, the calculating model in SESAM/GeniE is shown in Fig. 10. The model in SESAM/HydroD is shown in Fig. 11.

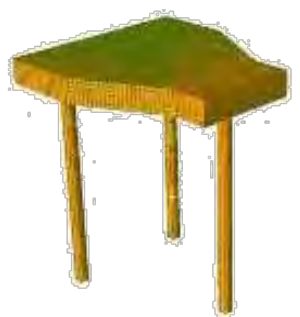

Fig. 10 Model in GeniE

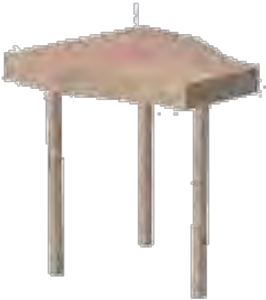

Fig. 11 Model in HydroD

\section{Hydrodynamic Analysis of the Jack-up}

While the spud-can of the jack-up is driving downwards, the jack-up platform is floating ${ }^{[11]}$. And the hydrodynamic responses of the vessel can be predicted at the spud-can's depth of $3 \mathrm{~m}, 10 \mathrm{~m}, 20 \mathrm{~m}$ and $38 \mathrm{~m}$, respectively.

\section{Hydrodynamic Response before the Pile Driven Down}

When the spun-cans are in the highest position, before they are driven downwards, the hydrodynamic responses of the platform can be calculated, by using SESAM software. And the roll response is shown in Fig.12. The sway response is shown in Fig.13. The pitch is shown in Fig.14. The surge response is shown in Fig.15. The yaw response is shown in Fig.16. And the heave response is shown in Fig. 17.

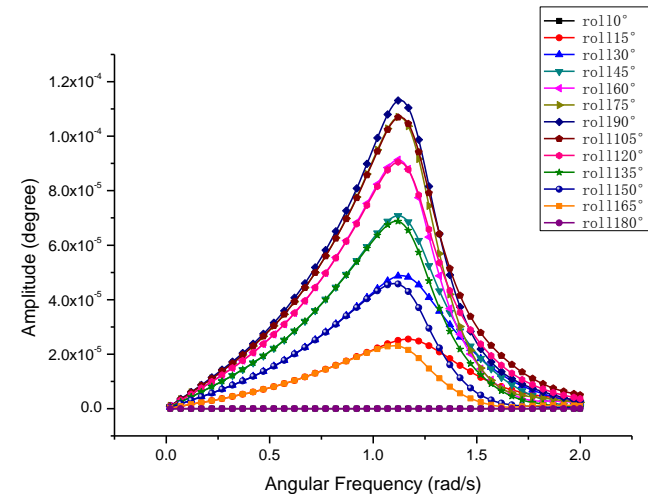

Fig. 12 The Response Amplitude of Roll(LC1)

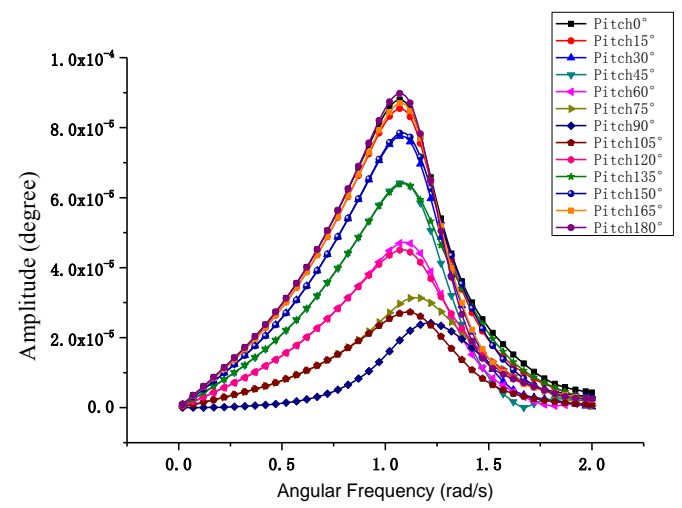

Fig. 14 The Response Amplitude of Pitch(LC1)

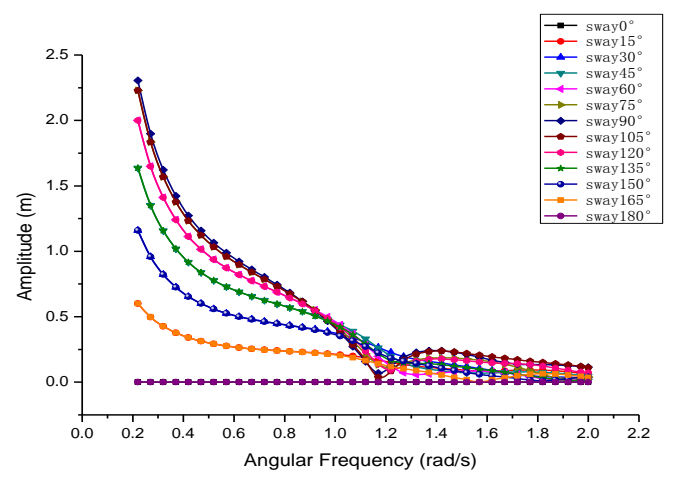

Fig. 13 The Response Amplitude of Sway(LC1)

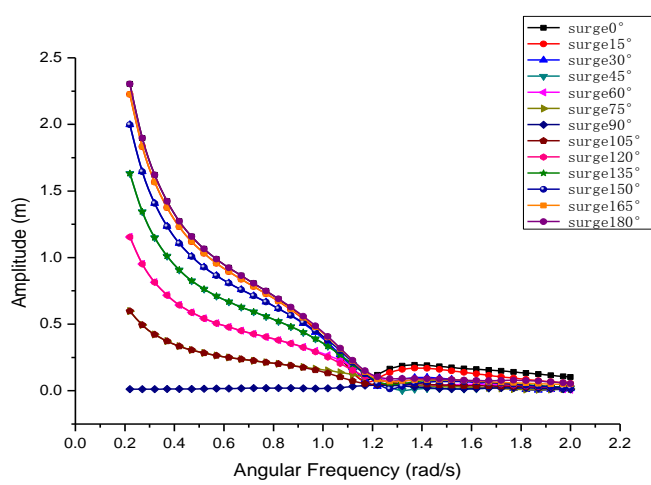

Fig. 15 The Response Amplitude of Surge(LC1) 


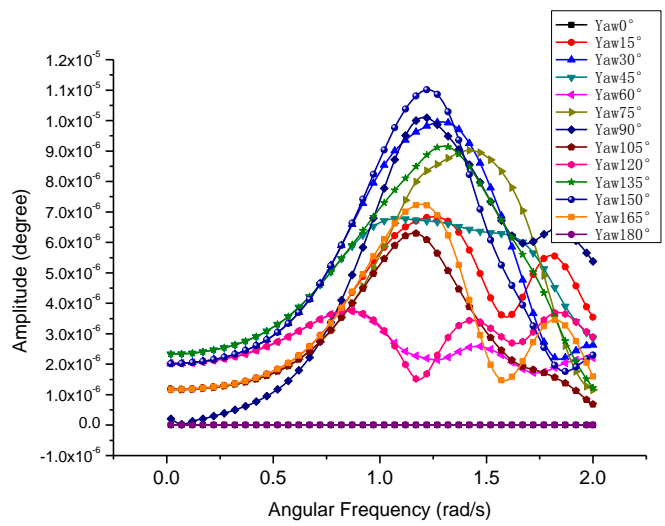

Fig. 16 The Response Amplitude of Yaw(LC1)

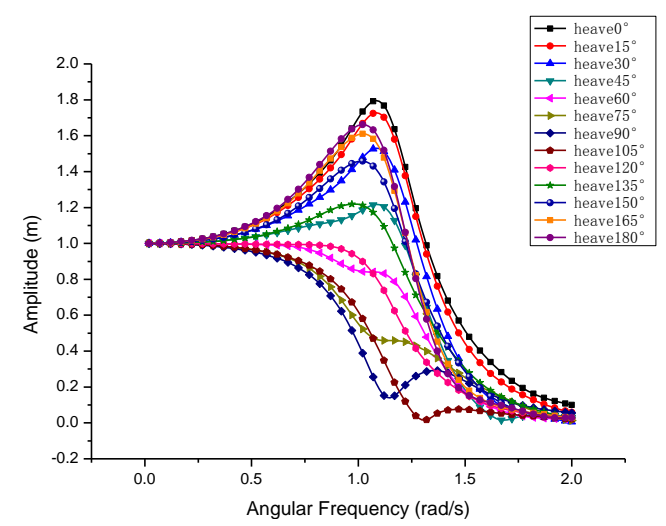

Fig. 17 The Response Amplitude of Heave(LC1)

Contrast the motional responses of the jack-up platform in six degrees of freedom, the roll and pitch of the structure reach to the maximum, when the angular frequency is $1.13 \mathrm{rad} / \mathrm{s}$. And the roll movement is the largest when the wave direction is $\beta=90^{\circ}$. The pitch movement is the largest when the wave direction is $\beta=120^{\circ}$. The yaw movement of the platform is in a complicated case, it reaches to the maximum when the wave direction is $\beta=120^{\circ}$, and, almost equal to zero while the wave direction is $\beta=180^{\circ}$.

The movements of sway and surge are mainly declined when the angular frequency enlarges. And the sway movement is the largest when the wave direction is $\beta=90^{\circ}$, while the surge of the platform is the largest when the wave direction is $\beta=120^{\circ}$. The heave movement reaches the extremum when the angular frequency is $1.2 \mathrm{rad} / \mathrm{s}$, and it reaches to the maximum at the wave direction of $\beta=0^{\circ}$, while to the minimum at the wave direction of $\beta=90^{\circ}$ and $\beta=105^{\circ}$.

\section{Hydrodynamic Response When the Spud-can at the Depth of $10 \mathrm{~m}$}

In load case 2, when the depth of the spud-can reaches to $10 \mathrm{~m}$, the hydrodynamic responses of the platform can be calculated by using SESAM software. And the result of roll response is shown in Fig.18. The sway is shown in Fig.19. The pitch response is shown in Fig.20. The surge response is shown in Fig.21. The yaw response is shown in Fig.22. And the heave response is shown as Fig.23.

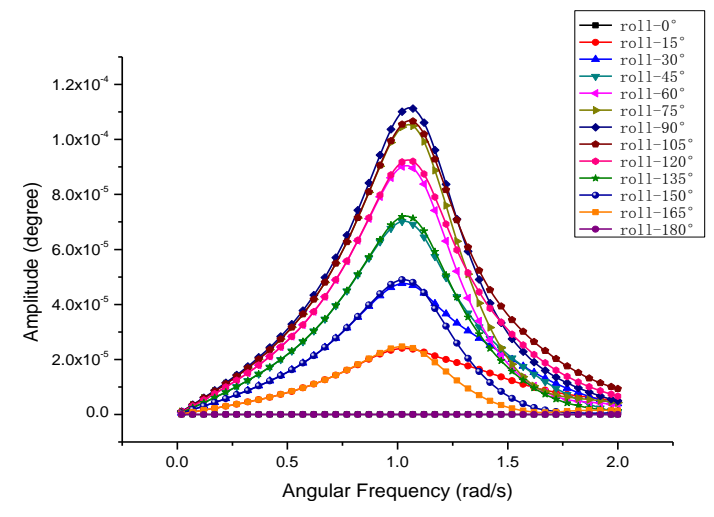

Fig. 18 The Response Amplitude of Roll(LC2)

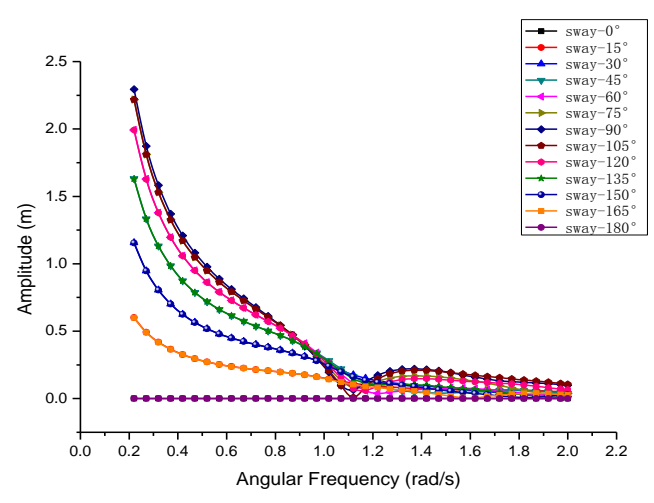

Fig. 19 The Response Amplitude of Sway(LC2)

The numerical results show that the roll and pitch of the platform reach to the peaks when the angular frequency is about $1.05 \mathrm{rad} / \mathrm{s}$, when the pile is falling $10 \mathrm{~m}$ into the sea. And the roll movement reaches the largest when the wave direction is $\beta=90^{\circ}$, while the pitch is the largest when the wave direction $\beta=0^{\circ}$. The yaw movement of the platform also is in complicated conditions, but it reaches to the maximum when the wave direction is $\beta=90^{\circ}$, almost to zero while the wave direction is $\beta=0^{\circ}$. 


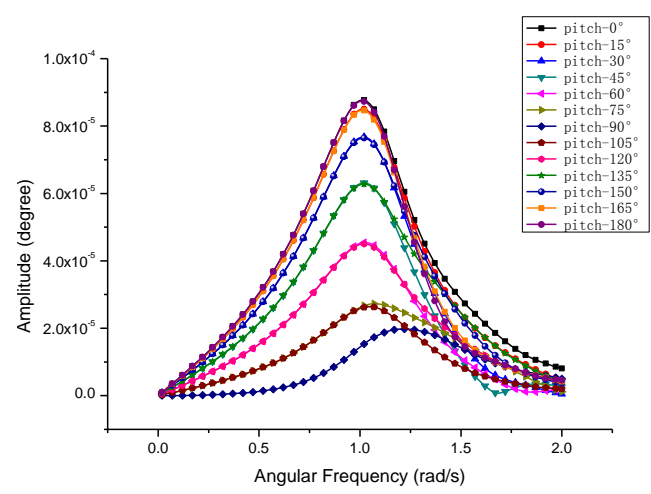

Fig. 20 The Response Amplitude of Pitch(LC2)

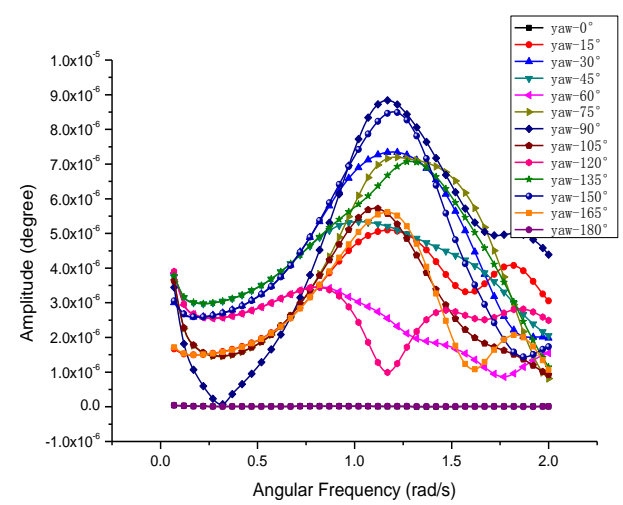

Fig. 22 The Response Amplitude of Yaw(LC2)

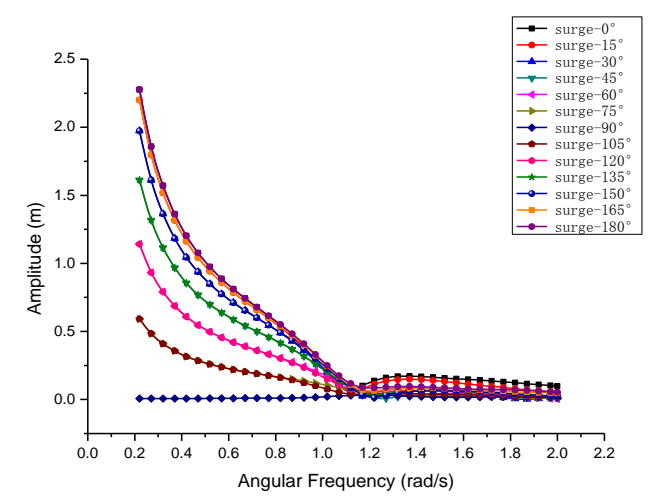

Fig. 21 The Response Amplitude of Surge(LC2)

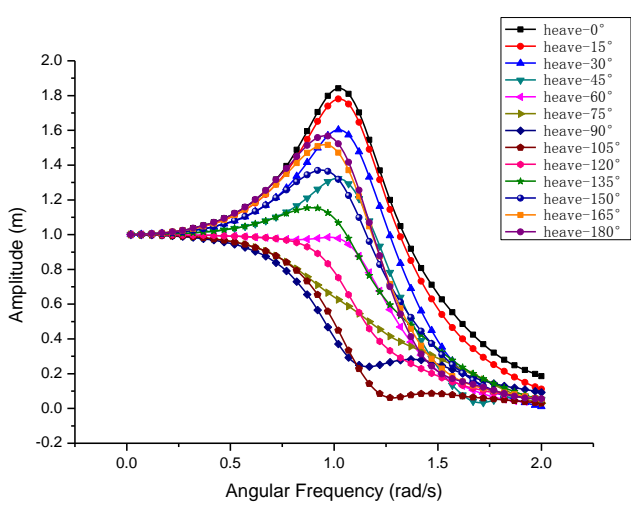

Fig. 23 The Response Amplitude of Heave(LC2)

Also, the movements of sway and surge are declined while the angular frequency enlarges. And the sway movement is the largest when the wave direction is $\beta=90^{\circ}$, while the surge of the platform is the largest when the wave direction is $\beta=0^{\circ}$. The heave movement reaches the extremum when the angular frequency is $1.2 \mathrm{rad} / \mathrm{s}$, and it reaches to the maximum at the wave direction of $\beta=0^{\circ}$, while to the minimum at the wave direction of $\beta=105^{\circ}$.

\section{Hydrodynamic Response When Spud-can at the Depth of 20m}

In load case 3 , when the depth of the spud can is $20 \mathrm{~m}$, the hydrodynamic responses of the platform are calculated. And the result of roll is shown in Fig.24. The sway is shown in Fig.25. The pitch response is shown in Fig.26. The surge response is shown in Fig.27. The yaw response is shown in Fig.28. And the heave response is shown in Fig.29.

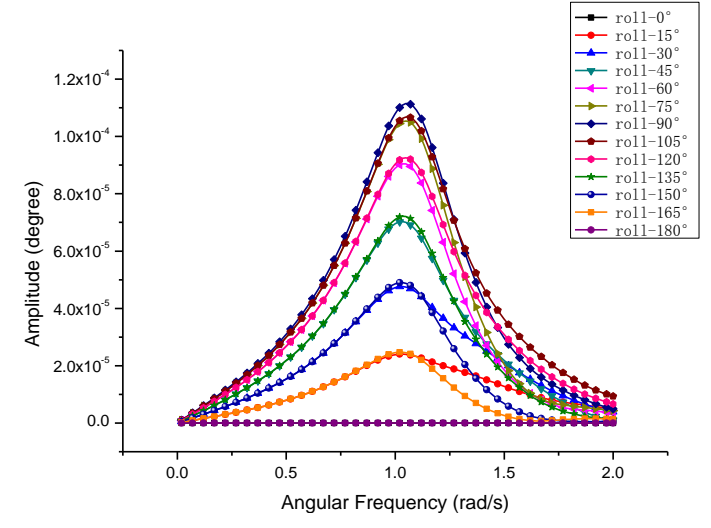

Fig. 24 The Response Amplitude of Roll(Lc3)

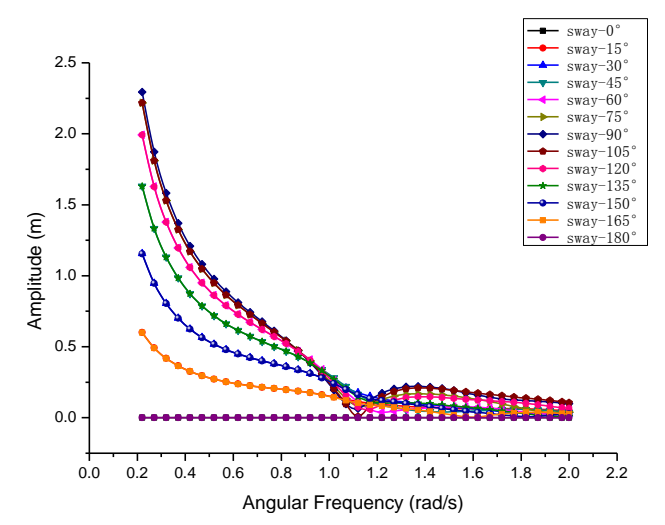

Fig. 25 The Response Amplitude of Sway(Lc3) 


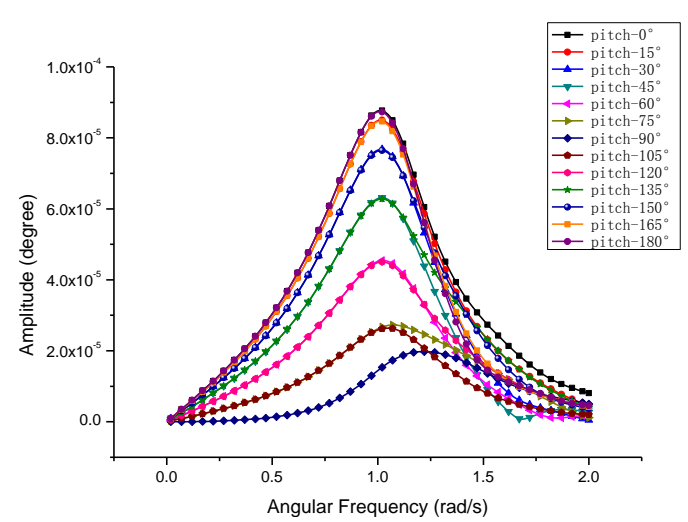

Fig. 26 The Response Amplitude of Pitch(LC3)

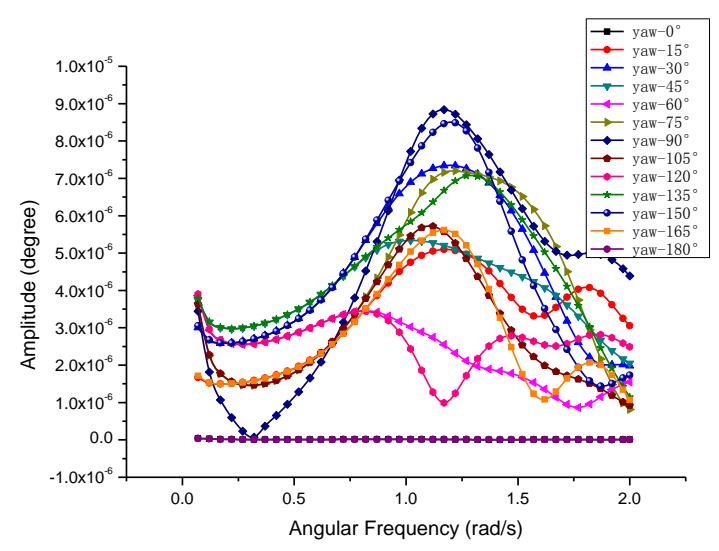

Fig. 28 The Response Amplitude of Yaw(1c3)

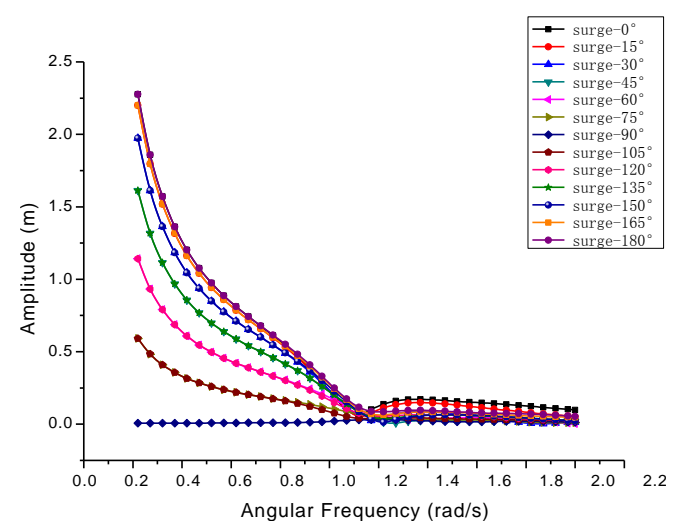

Fig. 27 The Response Amplitude of Surge(LC3)

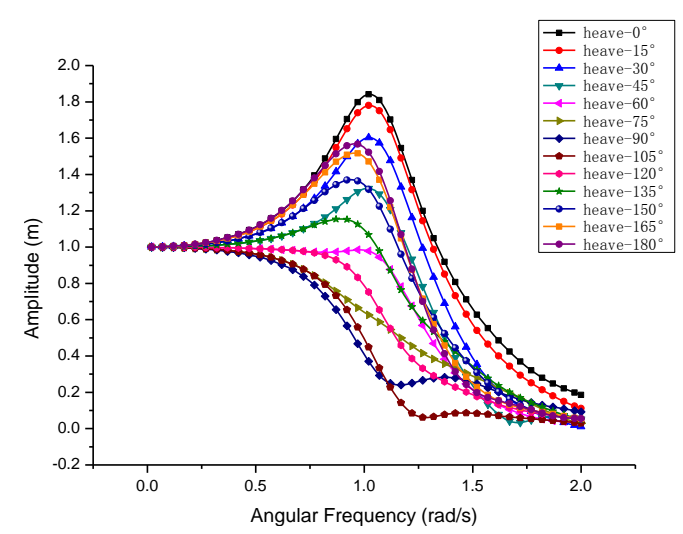

Fig. 29 The Response Amplitude of Heave (LC3)

The above results show that the roll and pitch of the platform reach the peaks when the angular frequency is nearly $1.05 \mathrm{rad} / \mathrm{s}$, when the pile is falling $20 \mathrm{~m}$ into the sea. And the pitch is the largest when the wave direction is $\beta=0^{\circ}$ and $\beta=180^{\circ}$. The movements of sway and surge decline evidently when the angular frequency enlarges. The heave movement reaches the extremum when the angular frequency is $1.1 \mathrm{rad} / \mathrm{s}$.

\section{Hydrodynamic Response before the Spud-can Touch down the Seabed}

In load case 4 , when the depth of the spud-can is $38 \mathrm{~m}$, the hydrodynamic responses of the platform can be calculated. And the roll is shown in Fig.30. The sway is shown in Fig.31. The pitch response is shown in Fig.32. The surge response is shown in Fig.33. The yaw response is shown in Fig.34. And the heave response is shown in Fig.35.

From the numerical results, when the pile is falling to the seabed, the roll and pitch of the platform reach the peaks when the angular frequency is $0.9 \mathrm{rad} / \mathrm{s}$, or even much smaller. The movements of sway and surge decline mainly when the angular frequency enlarges. The sway and surge reach to the extremum when the angular frequency is $0.8 \mathrm{rad} / \mathrm{s}$. The heave movement reaches the extremum when the angular frequency is $0.9 \mathrm{rad} / \mathrm{s}-1.1 \mathrm{rad} / \mathrm{s}$, and to the maximum at the wave direction of $\beta=0^{\circ}$, while to the minimum at the wave direction of $\beta=105^{\circ}$ to $120^{\circ}$.

From the results of the four load cases above, it is shown that, the roll and pitch movements of the jack-up are becoming smaller gradually when the depth of the spud-can increases. The reason is that the rotational moment of the structure increases when the spud-can being driven downwards. But the heave movement of the jack-up is becoming larger when the depth of the piles increase (when the angular frequency is $0.9 \mathrm{rad} / \mathrm{s}$ ). 


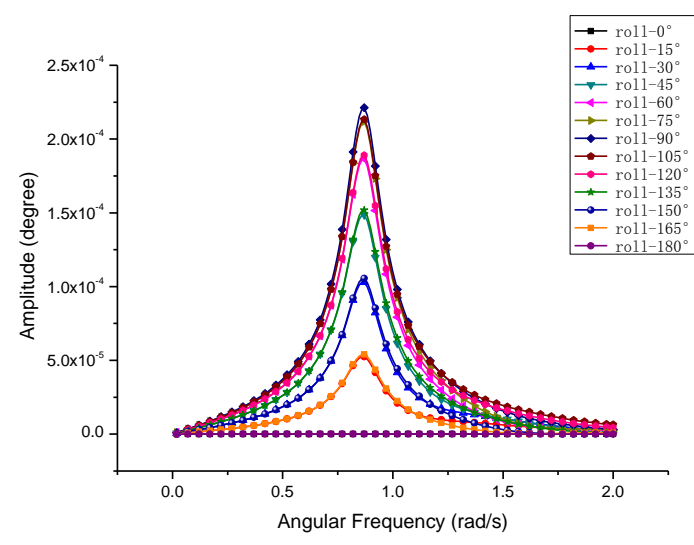

Fig. 30 The Response Amplitude Of Roll(LC4)

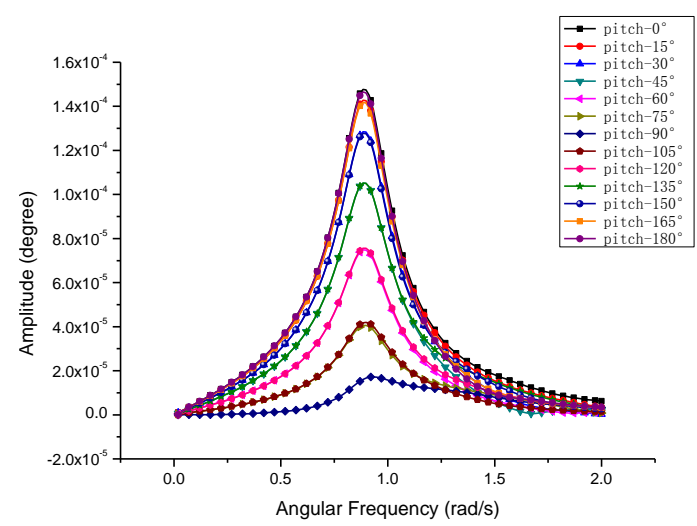

Fig. 32 The Response Amplitude of Pitch(LC4)

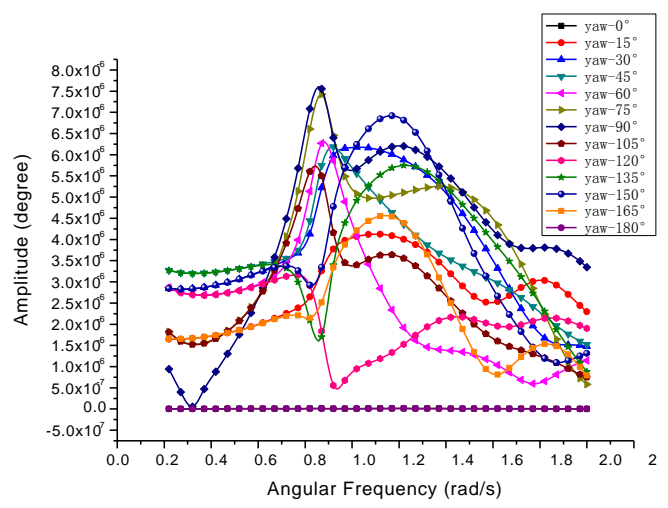

Fig. 34 The Response Amplitude of Yaw(LC4)

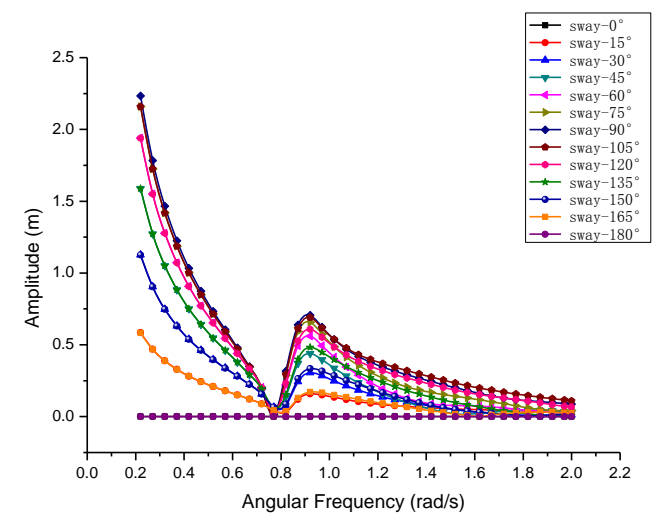

Fig. 31 The Response Amplitude of Sway(LC4)

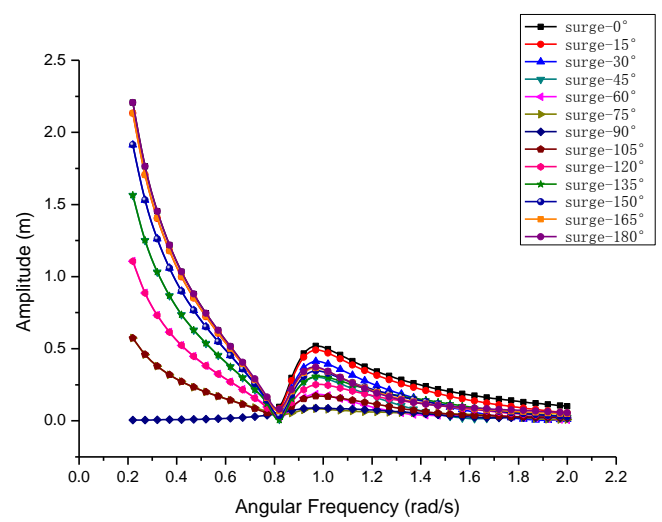

Fig. 33 The Response Amplitude of Surge(LC4)

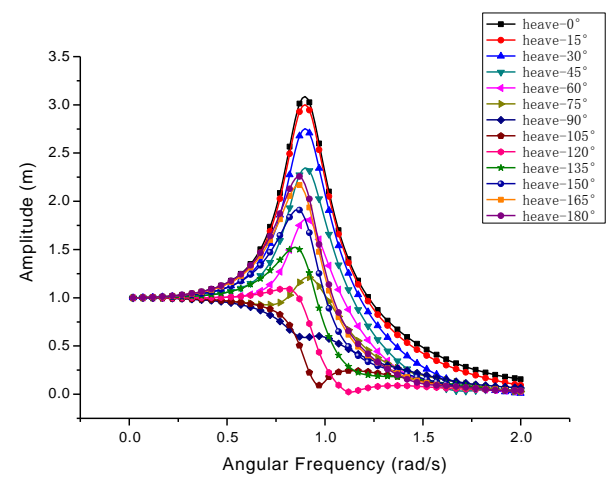

Fig. 35 The Response Amplitude of Heave(LC4)

\section{The Response Sensitivity of Different Wave Directions}

The heave responses of the jack up at load case 1,2,3 and 4, are compared, when the incident angle is $\beta=0^{\circ}, 45^{\circ}, 90^{\circ}$. The results of the three wave directions are shown in Fig. 36, 37 and 38, respectively. The surge responses of the jack-up at the four load cases, are also compared, when the incident angle is $\beta=0^{\circ}, 45^{\circ}, 90$. The results are shown in Fig. 39-41.

And the results of sway responses of the jack-up at the four load cases, when the incident angle is $\beta=0^{\circ}, 45^{\circ}, 90^{\circ}$ are shown in Fig. $42-44$.

The results show that, the heave response of the jack up at $\beta=90^{\circ}$, is much smaller than that of other wave directions. Especially, the angular frequency exceed $0.5 \mathrm{rad} / \mathrm{s}$. The surge response of the jack up at $\beta=90^{\circ}$, is smaller than that of other wave directions. Especially, when the angular 
frequency is below $0.5 \mathrm{rad} / \mathrm{s}$. The sway response at $\beta=0^{\circ}$ is much smaller than that of other wave directions.
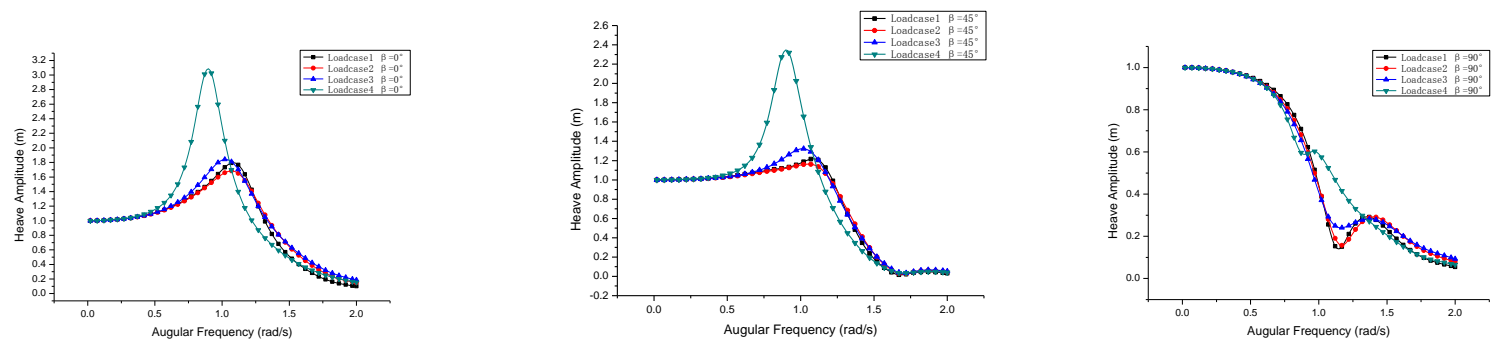

Fig. 36 Heave Response with $\beta=0^{\circ}$ Fig. 37 Heave Response with $\beta=45^{\circ}$ Fig. 38 Heave Response with $\beta=90^{\circ}$
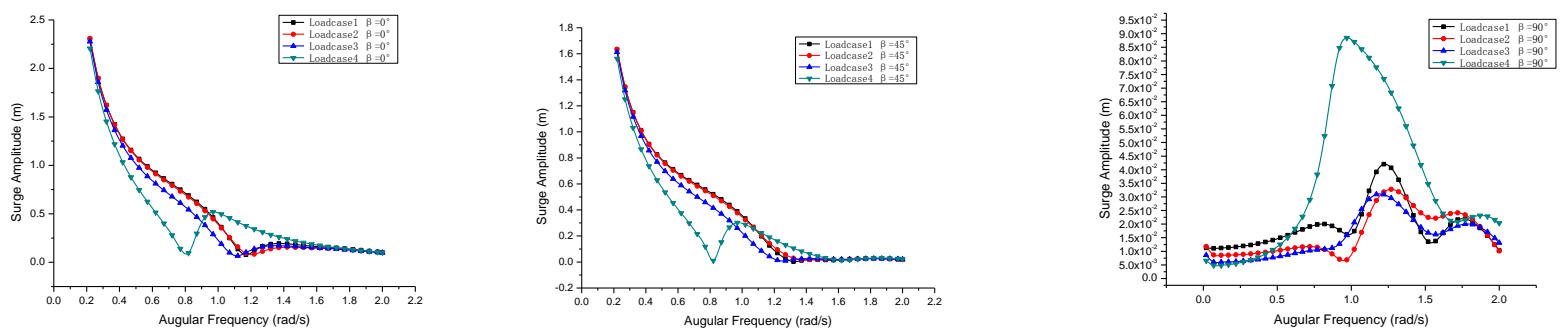

Fig. 39 Surge Response with $\beta=0^{0}$ Fig. 40 Surge Response with $\beta=45^{0}$

Fig. 41 Surge Response with $\beta=90^{\circ}$
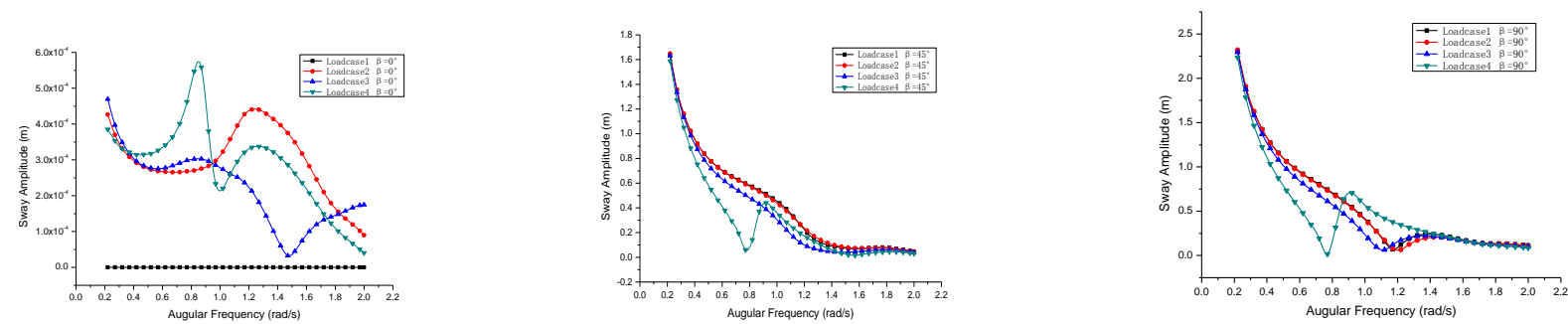

Fig. 42 Sway Response with $\beta=0^{\circ}$ Fig. 43 Sway Response with $\beta=45^{\circ}$ Fig. 44 Sway Response with $\beta=90^{\circ}$

\section{Conclusions}

(1) The heave, surge and sway response cannot be neglected during the floating state. The hydrodynamic responses have significant relationship with the nature period of the platform and low frequencies cause much bigger response amplitude, this phenomena is because the natural frequency of platform is much smaller than wave frequency, thus we get a bigger amplitude in low frequencies.

(2) The roll and pitch reach to maximum when the angular frequency is $1.15 \mathrm{rad} / \mathrm{s} \sim 1.13 \mathrm{rad} / \mathrm{s}$, and roll achieves the highest at $\beta=90^{\circ}$, while pitch is at $\beta=0^{\circ}$ and $\beta=120^{\circ}$. The case of yaw is very complicated, and it varies most when incident wave direction ranges from $\beta=90^{\circ}$ and $\beta=150^{\circ}$, almost zero at $\beta=0^{\circ}$.

(3) With the growth of angular frequency, surge and sway tend to be reduced and sway and surge is higher when direction is $\beta=90^{\circ}$ and $\beta=0^{\circ}$ respectively. The heave responses achieve its extreme value when the frequency is about $1.2 \mathrm{rad} / \mathrm{s}$, reaching to maxima and minima at $\beta=0^{\circ}$ and $\beta=90^{\circ}$.

(4) Coupling with the increase depth of spud-can, roll and pitch go downwards. The reason is that as the spud-can is driving downwards, the moment of inertia of whole platform is increasing, while amplitude of heave is becoming bigger, the reason is that inertia force and hydrodynamic force spud suffered keep increasing.

(5) The roll and pitch of the jack-up become smaller except when the incident angular frequency 
of wave is near $0.75 \mathrm{rad} / \mathrm{s} \sim 1 \mathrm{rad} / \mathrm{s}$. The sway and surge of the vessel grow when the incident angular frequency of wave is more than $0.8 \mathrm{rad} / \mathrm{s}$.

(6) The heave response of the jack up at $\beta=90^{\circ}$, is much smaller than that of other wave directions. The surge response of the jack up at $\beta=90^{\circ}$, is smaller than that of other wave directions. And the sway response at $\beta=0^{\circ}$, is much smaller than that of other wave directions.

\section{Acknowledgments}

This research work is financially supported by The National Natural Science Foundation of China (51179173 and 51379189).

\section{References}

[1]Puyang Zhang, Xiaoyang Yu, Hongyan Ding. Spudcan bearing capacity calculation of the offshore jack-up drilling platform during the preloading process [J]. Petroleum Exploration and Development. Vol.38 No.5. Oct. 2011. Pp613-619.

[2]George Vlahos, Mark J. Cassidy, Chris M. Martin. Experimental investigation of the system behaviour of a model three-legged jack-up on clay [J]. Applied Ocean Research. Vol.30 No.4. Oct .2008. Pp323-337.

[3]R.J. Siciliano, J.M. Hamilton, and J.D. Murff, Exxon Production Research Co., and R. Phillips, U. of Cambridge "Effect of Jackup Spud Cans on Piles" OTC 6467,1990.

[4]Jørgen Juncher Jensen, Julien Capul. Extreme response predictions for jack-up units in second order stochastic waves by FORM [J]. Probabilistic Engineering Mechanics. Vol.21 No.4. Oct. 2006. Pp330-337.

[5]Ping Liu, W.W. Massie, J.G. Wolters, and J. Blaauwendraad, Delft U. of Technology "Response of Jackup Models to Irregular Waves" OTC 6591, 1991.

[6]Naser Shabakhty. System failure probability of offshore jack-up platforms in the combination of fatigue and fracture [J]. Engineering Failure Analysis. Vol.18 No.1. Jan. 2011. Pp223-243.

[7]Jian Zhang, Chan Ghee Koh, Thanh N. Trinh, Xiaomei Wang, Zhen Zhang. Identification of jack-up spudcan fixity by an output-only substructural strategy [J]. Marine Structures. Vol.29 No.1. Dec. 2012. Pp71-88.

[8]B. Bienen, M.J. Cassidy. Advances in the three-dimensional fluid-structure-soil interaction analysis of offshore jack-up structures [J]. Marine Structures. Vol.19 No.2-3. Apr.-Jul. 2006. Pp110-140.

[9]Daniel Karunakaran, Mortern Barheim, Nils Spidsoe, Full-scale measurements from a large deepwater jack-up platform, Marine Structures 12(1999)255-275.

[10]Martin S.Williams, Richard S.G.Thompson, Guy T.Houlsby, non-linear dynamic analysis of offshore jack-up units, Computers and Structure 69(1998)171-180.

[11]A.C. Morandi, MSL Engineering Ltd., D. Karunakaran, SINTEF Civil and Environmental Engineering, A.T. Dixon, Health and Safety Executive, and M. Baerheim, STATOIL "Comparison of Full-Scale Measurements and Time-Domain Irregular Sea Analysis for a Large Deepwater Jack-Up" OTC, 8828, 1998. 